\title{
Juliette Reeves: 'We are going to find ourselves at the leading edge of preventive medicine'
}

Please send any ideas for feature articles for consideration to:

Ruth Doherty,

Managing Editor,

British Dental Journal,

The Macmillan Building,

4-6 Crinan Street,

London,

N1 9XW

Email: r.doherty@nature.com

Juliette Reeves, dental hygienist, on what we should be eating in the future, what is in store for preventive dentistry and the importance of research in establishing the links between oral diseases, nutrition and general health.

\section{Why did you choose to study nutrition?}

Back in 1993, I was working full time as a hygienist but was feeling disillusioned - a bit like a 'scale and polish machine'. I was considering taking a side step to something else healthcare related but I didn't know to what exactly. Then I saw a course on nutrition for healthcare professionals which I decided to do as I already knew a bit about nutrition and felt it might be revision for me. What I learnt in the first two days of that course made me realise that I didn't know anything about nutrition at all!

A lot of the things I was learning about the biochemistry of nutrition was answering questions for me raised by my own patients' cases. For example, I had a young female patient, 20 years old, with beautiful oral hygiene and perfect gum condition but still suffering gum recession. She hadn't changed her brushing, there was no plaque around and so there was nothing I could get a handle on to explain the recession. She wanted me to do something to help her to stop it happening but I couldn't do much aside from telling her to floss or brush more often, which I knew wouldn't work. It was on the nutrition course that I started to understand more about stress and calcium metabolism, and how this might be leading to her problems. That was 20 years ago when we didn't really think the mouth was part of the body. It was almost

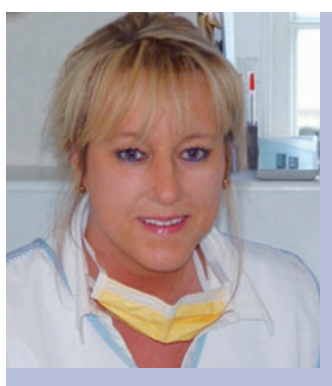

Juliette Reeves qualified as a dental hygienist from Birmingham Dental Hospital in 1981 and has more than thirty years experience in treating periodontal disease. She is also a trained nutritionist and has lectured internationally on the systemic associations between nutrition and oral health. Juliette writes regularly for the international dental press and is an editorial advisor to a number of dental journals, including Irish Dentist and Dental Hygiene and Therapy. Her work has been translated and published in the USA, Asia-Pacific region and Eastern Europe. Juliette is a senior UK tutor to the Swiss Dental Academy and clinical director of Perio-Nutrition (www. perio-nutrition.com). She is also an elected Association of Dental Implantology UK (ADI) committee member. Juliette works on behalf of the Wrigley Oral Healthcare Program as a media spokesperson and is secretary to the Eastern Regional British Society of Dental Hygiene and Therapy (BSDHT) Group.

considered 'alternative' to consider it as part of the whole body.

At that point I started to look at the evidence base and research around nutrition and oral health. I decided that I would really like to understand nutrition more so I did a two-year course on the subject. Then I started to do my own research; pulling all the periodontal and oral health research together to try to marry the two. That's basically what I've been doing for the last 20 years. Hygiene is what I love and the nutrition element helped me to rediscover what it was about hygiene that I really loved.

The key turning point to this research was probably about ten years ago when we started to look at the systemic associations. Suddenly the mouth became part of the body and when that happened it opened the doors for everything else, particularly nutrition. Now we have some very eminent scientists working on inflammation and nutrition.

\section{What is the most challenging aspect to being a hygienist?}

The most challenging thing is changing patients' behaviour, whether it be encouraging them to use interdental brushes everyday or changing their nutrition. Nutrition in particular is an emotional subject. When you start asking people about their diet they get defensive and can get upset, whereas if you ask them about their brushing you usually get a very different response.

Initially, when I was studying biochemistry I would give my patients all the background science about why they should eat certain things and generally they would respond with a glazed look on their face. I slowly realised that all they really wanted to know was what to eat and what not to eat. So now I simplify everything, and am supportive and encouraging. I'm not the kind of person who tells a patient off. It is important to give patients positives about what they are doing right and also helping 
them to see how that's going to change not only their oral health for the better but their systemic health as well.

\section{Do you feel nutrition is as central as it should be to dentistry?}

I think eventually it will become a key issue. We know from our own experience in practice that if you change a patient's diet their oral health gets better. This is anecdotal evidence which isn't valueless; in fact it's what drives research. However, what we need now is more long-term, focused research in terms of intervention and placebo-controlled trials. Unfortunately, long-term research is expensive. Ultimately, as we understand more about the role of oral health and its relationship with systemic health, as professionals we are going to find ourselves at the leading edge of preventive medicine, let alone preventive dentistry. Patients come to see a dental care professional whether they are sick or not - often at least twice a year - unlike the doctor. We are seeing them when they consider themselves healthy and so we are in a better position to offer preventive care.

\section{What are the challenges to the public health message around nutrition?}

There are a lot of fad diets and misinformation out there which patients seem to pick up on and that can make things difficult to spread the right message. That is why I always concentrate on the evidence base. In terms of getting oral health messages and nutrition messages to the public we rely on the media. For those patients that never come and see us (I think it is one in three patients don't have a dentist), we rely on the big organisations and their high profile campaigns. For example, the BDHF Smile Month campaign brings together leading companies who are able to put the information across. Once the patients are with us we can educate and advise them ourselves.

\section{What has been the biggest breakthrough in dental hygiene and nutrition?}

I think this has been our understanding of inflammation. We always thought that once you took away the causal factors for inflammation (ie removed the plaque or bacteria causing the infection) that it sort of died away on its own - a passive reaction. However, what we understand now is that inflammation has a biochemical trigger which needs to be activated for it to go from chronic to resolving. A lot of the work on this topic is being done by Professors Thomas Van Dyke and Charles Serhan who are looking at a new family of lipid mediators that resolve inflammation. They have just defined a family called resolvins, resolvins $\mathrm{E}$ and resolvins $\mathrm{D}$, which come exclusively from omega-3 fatty acids, which are found in the diet. Essential fatty acids are not synthesised by the body, they are essential because we must get them from the diet. The work that Professors van Dyke and Serhan are doing is showing us that unless we have adequate amounts of omega- 3 fatty acids in the diet then the ability for the body to trigger the resolution of the inflammation will be impaired. I'm sure that they will be awarded an amazing honour for this discovery because chronic inflammation underpins all diseases.

\section{What effect do you feel the emerging links between periodontology and systemic health will have on dentistry in the future?}

We are still looking for the bidirectional link that connects everything. We know that there are lots of associations between periodontology and other diseases, and that there are lifestyle and confounding factors that appear in all the systemic diseases. For me it's looking like the link may be chronic inflammation/oxidative stress. We know that oxidative stress can be attenuated by putting enough antioxidants into the body and that these come from the diet. If that is proved to be the link it would be hugely influential in the way in which we give our nutritional information and advice.

At the moment people are not getting enough antioxidants for a number of reasons. Fruit and vegetables are a major source of antioxidant intake and the UK government recommends that we eat five portions of fruit and veg a day. However, the last diet and nutrition survey for the UK showed that on average we are getting about 2.3 portions. So despite high profile campaigns people are still not eating even the basic amount. Five portions of fruit and veg a day is the minimum really, we should really be eating more.

Another factor is that antioxidants are used up when there is a lot of free radical activity. Free radicals attack cell membranes and antioxidants are needed to quench the attack to prevent the membrane from breaking down. Free radicals come from many sources which include barbequed foods, environmental sources (pollution) and smoking. So there are lots of environmental influences which increase the amount of oxidative stress. We are not getting enough antioxidants from fruit and veg to balance out the increase in free radicals in our systems.

\section{You lecture internationally - has any trip in particular stood out for you?}

The most exciting thing I did recently was Europerio 7 in Vienna. To be surrounded by all those incredibly gifted and focused individuals doing periodontics research was fantastic. I presented two papers there - one was about omega-3 fatty acids and the work that Serhan and van Dyke were doing. They also gave presentations there and I had the opportunity to meet them which was great. They were so knowledgeable and have a vast amount of experience in the field.

I did another paper on telomeres.

Telomeres are a bit like the ends of a shoe lace that protect our DNA strands. As they get shorter and shorter the DNA strand will unravel, killing the cell. Oxidative stress is one of the things that shortens the telomeres. So again I was able to talk to people who had more experience in that area than me. It was so exciting and Vienna is really beautiful.

\section{To what extent do you feel that dentists buy into nutrition and 'complementary medicine'?}

The majority of work I have done around nutrition has been hygienist-focused but I have always had dentists on board. Now when I am lecturing and teaching I am getting an increasing number of dentists involved. They are more interested 
as the evidence base grows stronger and as the systemic associations become significantly established. For us, as professionals, before we can fundamentally recommend a course of action we need to be comfortable and confident that the evidence base is there to support it.

Our patients drive research too. They will come in and say, 'I've read an article about this, what do you think I should do?' How many of us have been treating a patient for periodontal disease and they ask, "is there anything I can eat that will make this better?' I don't think any of us are in the situation now where we can shrug our shoulders and say no there isn't because we know that the research to support nutritional effects is out there.

\section{If you were Prime Minister what would you want to do?}

I think the key thing has got to be to increase access to dental services. We need to give the public access to both the treatment and the information they need. Huge sections of the population can't get access to a dentist. People also need more access to education in terms of nutrition and oral health. Education should be taken out of the solely clinical setting and moved into the high street and other healthcare environments.

\section{What do you see us eating for dinner in 20 years' time?}

I think we've been through the fast food and processed food phase now. We have seen the cost of food being driven down by manufacturers manipulating it to make it appear to be something that it's not. I would like to see the whole system come right round again to where we have traditional farming methods and we are eating seasonal food. Food should be produced locally rather than being shipped halfway across the world in oxygen-free environments. We now eat food that we think is fresh but it is actually three months old. That is going to be hard to change but that's what I want. If I were Prime Minister for a year that's what I would do! Part of the problem is that it is time consuming and we are all out at work now. We no longer live off the farm so time management and eating the right food is a big issue.

\section{What are your views on direct access?}

I think direct access will benefit patients greatly. We often get patients in our practice who will have their own dentist in another city but find it much easier to see a hygienist around the corner and they may not particularly want to ask their dentist for a referral.

I also see direct access as a way of channelling patients who would not normally come into the dental system back to dental practices for treatment. Seeing a hygienist may be their first experience and probably nine times out of ten they will come in for cosmetic reasons. But once we have them in the system we can educate them and send them to dentists to get the restorative work done and to look after their oral health. I see that as a positive thing. It is a net that will capture more of the population that are not coming regularly to the dentist.

Interview by Ruth Doherty 